\title{
Quality evaluation of intact açaí and juçara fruit by means of near infrared spectroscopy
}

\author{
Luis Carlos Cunha Júnior ${ }^{\mathrm{a}, *}$, Gustavo Henrique de Almeida Teixeira ${ }^{\mathrm{b}}$, Viviani Nardinic \\ Kerry Brian Walsh ${ }^{\mathrm{d}}$ \\ a Universidade Federal de Goiás (UFG), Escola de Agronomia (EA), Setor de Horticultura, Rodovia Goiânia/Nova Veneza, Km 0-Campus Samambaia, 74.690- \\ 000 Goiânia, GO, Brazil \\ b Universidade Estadual Paulista (UNESP), Faculdade de Ciências Agrárias e Veterinárias de Jaboticabal (FCAV), Via de acesso Prof. Paulo Donato Castellane s/ \\ n, Jaboticabal, São Paulo CEP 14.884-900, Brazil \\ ${ }^{\mathrm{C}}$ Universidade de São Paulo (USP), Faculdade de Ciências Farmacêuticas de Ribeirão Preto (FCFRP), Departamento de Análises Clínicas, Toxicológicas e \\ Bromatológicas, Av. do Café s/n-Campus Universitário da USP, Ribeirão Preto, São Paul, CEP 14.040-903, Brazil \\ ${ }^{\mathrm{d}}$ Central Queensland University, Plant Sciences Group, Rockhampton 4702, Queensland, Australia
}

\section{A R T I C L E I N F O}

\section{Article history:}

Received 23 April 2015

Received in revised form 25 September 2015

Accepted 5 October 2015

Available online 24 October 2015

\section{Keywords:}

Anthocyanin

Euterpe oleracea Mart

Euterpe edulis Mart

Classification

Partial least squares regression

Soluble solids content

\begin{abstract}
A B S T R A C T
The objective of this study was to report the robustness of partial least squares regression (PLSR) models developed using FT-NIR reflectance spectra obtained from intact açaí and juçara fruit. Mature fruit were collected over two years ( 6 populations of açaí and juçara, totalling 505 samples). Diffuse reflectance spectra were acquired ( 64 scans and spectral resolution of $8 \mathrm{~cm}^{-1}$ ) using $\sim 25$ fruits per batch on a $90 \mathrm{~mm}$ diameter glass dish in a single layer. Spectra were subject to several pre-processing procedures and two variable selection methods to develop the PLSR models. For total anthocyanin content (TAC) in açaí, a PLSR model developed using the wavelength range of $1606-1793 \mathrm{~nm}$, standard normal variate (SNV) and second derivative of Savitzky-Golay (SNV $+d^{2} A$ ) achieved a bias corrected root mean square error (SEP) of $3.6 \mathrm{~g} \mathrm{~kg}^{-1}$ and a $R_{\mathrm{p}}^{2}$ of 0.7 in predicting an external independent set, which was better than PLSR models for juçara (SEP of $3.7 \mathrm{~g} \mathrm{~kg}^{-1}, R^{2}$ p of 0.5 ), and for both species combined (SEP of $5.7 \mathrm{~g} \mathrm{~kg}^{-1}, R_{\mathrm{p}}^{2}$ of 0.5 ). For soluble solids content (SSC) in açaí the models developed using SNV $+d^{2} A$ spectra over the window of $1640-1738 \mathrm{~nm}$ achieved a bias-corrected SEP of $2.9 \%$ and $R_{\mathrm{p}}^{2}$ of 0.8 , similar to juçara (SEP of $1.1 \%, R_{\mathrm{p}}^{2}$ of 0.9 ) and for both species combined (SEP of $2.3 \%, R_{\mathrm{p}}^{2}$ of 0.8 ). The developed models can be used to sort açaí and juçara based on SSC and TAC into two grades (low and high contents).
\end{abstract}

(c) 2015 Elsevier B.V. All rights reserved.

\section{Introduction}

Among the Brazilian palm species açaí (Euterpe oleracea Mart.) and juçara (Euterpe edulis Mart.) are mentioned as "super foods" (Smith, 2013). Açaí is endemic in the Amazonian floodplains (Santos and Jardim, 2006) and juçara in the Atlantic Forest (Inácio et al., 2013). The fruit of both species mature within approximately $180 \mathrm{~d}$ after flowering, with a single bunch containing fruit with a wide range of maturity (Calvi and Pina-Rodrigues, 2005; Pessoa and Teixeira, 2012). A typical fruit of both species weighs around $2 \mathrm{~g}$ of which $15 \%$ is the exocarp and mesocarp (pulp) surrounding a single seed (Borges et al., 2011; Schauss et al., 2006a; Schauss et al., 2006b). Fruit is purple when ripe as a result of anthocyanin

\footnotetext{
* Corresponding author.

E-mail address: cunhajunior.l.c@gmail.com (L.C. Cunha Júnior).
}

accumulation in the exocarp and mesocarp tissues during fruit maturation (Gordon et al., 2012).

These fruits have been promoted for their functional properties, linked to an exceptionally high antioxidant activity (Poulose et al., 2012), which in turn is associated with a high anthocyanin content (Inácio et al., 2013), with values typically an order of magnitude greater than that is reported in red wine grape (Ferrer-Gallego et al., 2011; Schauss et al., 2006a). Açaí and juçara pulp extracts have demonstrated effectiveness to combat some of the inflammatory and oxidative mediators involved in ageing (Poulose et al., 2012). There is also potential to use the fruit as a source of coloring agent (anthocyanin) for the food industry (Vieira et al., 2013), as demand for natural colorants has increased by almost $35 \%$ from 2005 to 2009 (Foods, 2011). The main anthocyanins detected in the juçara and açaí fruits were identified as cyanidin3-glucoside and cyanidin3-rutinoside (Brito et al., 2007; Pessoa and Teixeira, 2012; Schauss et al., 2006b). The major current source of natural anthocyanin pigment used in the food industry is known as 
colorant E163 or enocyanin and is extracted from grape skins (Melo et al., 2009 Vieira et al., 2013).

The açaí and juçara postharvest fruit handling was presented by Pessoa and Teixeira (2012). On arrival at the processing plant, fruits are visually assessed based on defects (diseases, bruises, insect damage) and skin color (deep purple, as an index of fruit maturity). Fruits are then softened in water $\left(\sim 40^{\circ} \mathrm{C}\right)$, and processed in a juicer (Pessoa and Teixeira, 2012; Rogez et al., 2012). The pulp is standardized based on total solids content into three grades: A, >14\%; B, 11-14\%; and C, 8-11\%, as defined by the Brazilian Ministry of Agriculture and Husbandry (BRASIL, 2000).

With the fruit valued for its anthocyanin content, it is logical to grade fruit based on this compound concentration, as exists a wide variation in anthocyanin content among fruits on a single bunch and between harvest times, trees, origin, etc. For example, Malcher and Carvalho (2011) reported that anthocyanin content of açaí fruit harvested in December was 10 times higher on a per weight basis than fruit harvested in September. A wide variation in fruit external color exists between fruit of a bunch at any time of bunch harvest, from green or purple to deep purple-black (Inácio et al., 2013; Pessoa and Teixeira, 2012). While this color is an index of maturity, and linked to anthocyanin accumulation, it is not well correlated to absolute anthocyanin level. For example, fruit of same color (completely purple) from two localities was assessed to possess between $1.5-82.0 \mathrm{~g} \mathrm{~kg}^{-1}$ total anthocyanin content (TAC), on a pulp fresh weight basis (Inácio et al., 2013). Also, Rogez et al. (2011) noted the maximum TAC in açaí was achieved some time after development of $100 \%$ purple-black skin color, and the amount of waxy on the cuticle was suggested as an alternative maturity index, the relationship to TAC level was not demonstrated, though.
Near infrared (NIR) spectroscopy is a candidate analytical technology for fruit grading, conditional to the ability to create a robust calibration for this indirect analysis technique. Given the presence of a hard seed within a thin (1-3 mm thick) pericarp that contains the attributes of interest, reflectance spectroscopy is recommended over partial or full transmission geometry. Ferrer-Gallego et al. (2011) used reflectance spectra (wavelength range of $1100-2000 \mathrm{~nm}$ ) and partial least squares regression (PLSR) to estimate TAC of intact grape berries, reporting a root mean squared error of prediction (RMSEP) of $810-1100 \mathrm{mg} \mathrm{kg}^{-1}$ fresh weight. Cozzolino et al. (2004) acquired absorbance spectra over the wavelength range of $400-1100 \mathrm{~nm}$ of intact grape berries and berry homogenates. A root mean square error of cross calibration (RMSE $\mathrm{CV}_{\mathrm{CV}}$ ) of 60 and $140 \mathrm{mg}$ $\mathrm{kg}^{-1}$ fresh weight, and a ratio of the standard deviation (S.D.) ( $110 \mathrm{mg} \mathrm{kg}^{-1}$ ) to the standard error of calibration (RPD) of 4.2 and 1.8 , was achieved for of TAC of whole and homogenised grape, respectively.

Various procedures can be undertaken to ensure that a model is not over-fitted to a data set, causing inflated calibration statistics, e.g. careful selection of cross validation sets, and interpretation of model coefficients. However, variation in fruit properties between populations (in chemical composition, in cell density, etc.) exists, and in practical demonstration of the robustness of a model in predicting an attribute of interest in fruit grown under a range of conditions is required (Nicolaï et al., 2007; Subedi and Walsh, 2009). For example, diffuse reflectance spectra are sensitive to changes in sample surface layers (Lammertyn et al., 2000; Nicolaï et al., 2007). Different fruit batches vary in the amount of cuticle of wax over the exocarp, and also in the depth of edible tissue (exocarp and mesocarp, 1-3 $\mathrm{mm}$ to hard seed) (Pessoa and Teixeira,

Table 1

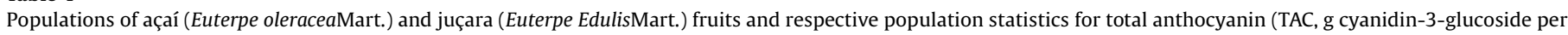
kilogram of fresh weight) and soluble solids content (SSC, \%).

\begin{tabular}{|c|c|c|c|c|c|c|c|c|c|c|c|c|c|}
\hline \multirow[t]{2}{*}{ Species } & \multirow[t]{2}{*}{ Locality } & \multirow[t]{2}{*}{ Year } & \multirow[t]{2}{*}{ Population } & \multicolumn{2}{|l|}{ TAC } & \multicolumn{2}{|l|}{ SSC } & \multirow[t]{2}{*}{$N$} & \multirow[t]{2}{*}{ Season } & \multicolumn{2}{|l|}{ TAC } & \multirow{2}{*}{$\frac{\text { SSC }}{\text { Mean }}$} & \multirow[b]{2}{*}{$\overline{\text { S.D. }}$} \\
\hline & & & & Mean & as.D. & Mean & S.D. & & & Mean & S.D. & & \\
\hline \multirow[t]{13}{*}{ Açaí (A) } & \multirow[t]{4}{*}{ Amer (i) } & \multirow[t]{2}{*}{2012} & \multirow[t]{2}{*}{ Pop 1} & \multirow[t]{2}{*}{11.16} & \multirow[t]{2}{*}{3.93} & \multirow[t]{2}{*}{17.27} & \multirow[t]{2}{*}{2.05} & 40 & June & 13.56 & 3.70 & 16.40 & 2.43 \\
\hline & & & & & & & & 39 & August & 8.68 & 2.39 & 18.16 & 1.03 \\
\hline & & \multirow[t]{2}{*}{2013} & \multirow[t]{2}{*}{ Pop 2} & \multirow[t]{2}{*}{2.78} & \multirow[t]{2}{*}{1.91} & \multirow[t]{2}{*}{11.52} & \multirow[t]{2}{*}{1.14} & 15 & May & 2.91 & 2.49 & 11.34 & 1.44 \\
\hline & & & & & & & & 10 & June & 2.59 & 0.67 & 11.78 & 0.49 \\
\hline & Jab1 (ii) & 2012 & Pop 3 & 15.08 & 2.17 & 23.23 & 1.34 & 14 & July & 14.63 & 2.49 & 23.23 & 1.39 \\
\hline & & 2013 & Pop 4 & 8.27 & 2.94 & 17.63 & 1.33 & 17 & May & 8.27 & 3.03 & 17.62 & 1.37 \\
\hline & Jab2 (iii) & 2012 & Pop 5 & 27.81 & 4.25 & 26.81 & 3.78 & 40 & July & 27.81 & 4.30 & 26.81 & 3.83 \\
\hline & & 2013 & Pop 6 & 27.81 & 6.66 & 26.51 & 6.07 & 40 & June & 29.95 & 6.73 & 29.60 & 5.40 \\
\hline & & & & & & & & 60 & July & 24.51 & 5.28 & 22.02 & 3.90 \\
\hline & $\mathrm{i}$ & $12-13$ & Pop 1-2 & 9.14 & 5.07 & 15.89 & 3.11 & 104 & & & & & \\
\hline & $\mathrm{i}+\mathrm{ii}$ & $12-13$ & Pop 1-3 & 9.85 & 5.16 & 16.76 & 3.79 & 118 & & & & & \\
\hline & $\mathrm{i}+\mathrm{ii}$ & $12-13$ & Pop 1-4 & 9.64 & 4.96 & 16.87 & 3.59 & 135 & & & & & \\
\hline & $\mathrm{i}+\mathrm{ii}+\mathrm{iii}$ & $12-13$ & Pop 1-5 & 13.80 & 9.03 & 19.14 & 5.54 & 175 & & & & & \\
\hline Juçara (J) & Amer (i) & 2012 & Pop 7 & 32.82 & 4.25 & 22.82 & 2.59 & 20 & June & 32.82 & 4.36 & 22.85 & 2.66 \\
\hline & & 2013 & Pop 8 & 20.68 & 3.85 & 21.27 & 1.42 & 20 & April & 20.68 & 3.95 & 21.27 & 1.46 \\
\hline & Jab1(ii) & 2012 & Pop 9 & 20.37 & 5.72 & 16.80 & 3.39 & 10 & March & 17.97 & 3.94 & 15.78 & 3.36 \\
\hline & & & & & & & & 30 & April & 27.58 & 4.27 & 19.84 & 1.46 \\
\hline & & 2013 & Pop 10 & 13.53 & 7.44 & 14.71 & 5.04 & 41 & April & 9.04 & 2.35 & 11.62 & 1.92 \\
\hline & & & & & & & & 19 & June & 23.23 & 5.19 & 21.39 & 2.76 \\
\hline & Rib(iv) & 2012 & Pop 11 & 18.53 & 7.53 & 17.94 & 5.07 & 30 & March & 13.37 & 4.14 & 14.29 & 2.67 \\
\hline & & & & & & & & 10 & April & 30.41 & 2.08 & 25.02 & 1.26 \\
\hline & & & & & & & & 30 & June & 19.74 & 6.37 & 19.22 & 4.66 \\
\hline & & 2013 & Pop 12 & 4.77 & 4.98 & 9.55 & 2.73 & 10 & February & 9.38 & 2.80 & 12.21 & 0.62 \\
\hline & & & & & & & & 10 & April & 0.16 & 0.05 & 6.89 & 0.74 \\
\hline & i & $12-13$ & Pop 7-8 & 26.75 & 7.39 & 22.05 & 2.25 & 40 & & & & & \\
\hline & $\mathrm{i}+\mathrm{ii}$ & $12-13$ & Pop7-9 & 23.56 & 7.34 & 19.42 & 3.91 & 80 & & & & & \\
\hline & $\mathrm{i}+\mathrm{ii}$ & $12-13$ & Pop 7-10 & 19.26 & 8.90 & 17.40 & 5.01 & 140 & & & & & \\
\hline & $\mathrm{i}+\mathrm{ii}+\mathrm{iv}$ & $12-13$ & Pop 7-11 & 19.02 & 8.47 & 17.58 & 5.04 & 210 & & & & & \\
\hline$J+A$ & $\mathrm{i}$ & $12-13$ & Pop $1-2 ; 7-8$ & 12.96 & 10.00 & 17.60 & 3.99 & 144 & & & & & \\
\hline & ii & $12-13$ & Pop 3-4;9-10 & 15.10 & 7.26 & 16.64 & 4.71 & 131 & & & & & \\
\hline & $\mathrm{iii}+\mathrm{iv}$ & $12-13$ & Pop 5-6+11-12 & 23.00 & 9.53 & 22.50 & 7.62 & 230 & & & & & \\
\hline & $\mathrm{i}+\mathrm{iii}+\mathrm{iv}$ & $12-13$ & Pop $1-2+5-8+11-12$ & 19.56 & 10.56 & 20.62 & 6.90 & 374 & & & & & \\
\hline
\end{tabular}

a S.D.: standard deviation. 
2012; Rogez et al., 2011), such that a model based on one population may perform poorly in prediction of fruit from different growing conditions.

Kiozimi et al. (2013) reported the use of reflectance NIR (1000$2500 \mathrm{~nm}$ ) spectroscopy to assess SSC in açaí pulp, achieving a RPD value of 3.3 and RMSEP of $0.95 \%$. This study employed a Spectrum 100N FTNIR (PerkinElmer, Shelton, CT) unit with a reflectance probe. Using the same equipment, Inácio (Inácio et al., 2013) reported the use of reflectance NIR $(900-2500 \mathrm{~nm})$ spectra to assess TAC in intact juçara and açaí fruit, with a ratio of the S.D. of TAC of the prediction set ( $14.8 \mathrm{~g} \mathrm{~kg}^{-1}$ ) to a RMSEP of $4.8 \mathrm{~g} \mathrm{~kg}^{-1}$ (S.D. $R \mathrm{p})$ of 3.1 for the combined population. However, both studies employed only one data set of fruit, divided into two groups by Kennard-Stone selection, calibration and validation sets. As such, the reported RMSEP value is not indicative of the ability of the model to predict fruit outside the population used in calibration.

The objective of this study was to document robustness of PLSR models developed using FT-NIR reflectance spectra obtained from intact açaí (E. oleracea Mart.) and juçara (E. edulis Mart.) fruit to estimate SSC and TAC.

\section{Materials and methods}

\subsection{Plant material and spectra acquisition}

Plant material and spectral acquisition were conducted as reported by Cunha Junior et al. (2005). Briefly, açaí (E. oleracea Mart.) and juçara (E. edulis Mart.) fruit bunches were harvested at commercial maturity stage at several times during the cropping season at four localities (within Sao Paulo State, Brazil), and in two years (2012 and 2013). Açaí fruit were harvested at (i) Américo Brasiliense (Amer); (ii) Jaboticabal (Jab 1); and (iii) in an urban vegetable garden in Jaboticabal (Jab 2). Juçara fruit were harvested from same (i) and (ii) locations, and (iv) in Ribeirão Preto (Rib.). After harvest, fruit temperature was stabilized $\left(\sim 25^{\circ} \mathrm{C}\right)$, and $4-$ 10 lots of 20-30 fruit each were randomly selected from each bunch, creating a total of 505 samples across the twelve populations of locations and species (Table 1 ).

Samples (20-30 fruit) were placed onto a $90 \mathrm{~mm}$ diameter glass dish (PerkinElmer, ref. L118 1257, EUA) in a single layer. The dish was placed on the Near Infrared Reflectance Accessory of a FT-IR Spectrum 100N (PerkinElmer, Shelton, CT, USA) spectrometer. Diffuse reflectance spectra were obtained over the range of 4000$10,000 \mathrm{~cm}^{-1}(1000-2500 \mathrm{~nm})$ at a spectral resolution of $8 \mathrm{~cm}^{-1}$ with 64 scans per spectra. The log $1 /$ Reflectance spectra are referred to as absorbance spectra for convenience. Three spectra were acquired per sample, with mixing the fruits between the acquisitions of each spectrum. After spectra acquisition, samples were rapidly frozen and stored at $-18^{\circ} \mathrm{C}$.

\subsection{Sample preparation and reference analysis}

The exocarp and mesocarp of each sample (20-30 fruit) were separated from the endocarp (stone) using a stainless steel knife, and the pulp material, approximately $9 \mathrm{~g}$, was macerated using a porcelain mortar and pestle (Inácio et al., 2013). The pulp material was then stored at $-18{ }^{\circ} \mathrm{C}$ for total anthocyanin content (TAC) and soluble solids content (SSC) determination.

\subsection{Total anthocyanin content (TAC)}

The total anthocyanin content was determined in the $1 \mathrm{~g}$ of pulp material using the A.O.A.C reference method (AOAC, 2006) and expressed in grams of cyanidin-3-glucoside per kilogram of fresh weight. The calculated TAC ranged from 0.1 to $43.9 \mathrm{~g} \mathrm{~kg}^{-1}$ (Table 1 ).

\subsection{Soluble solids content (SSC)}

A sub-sample (approx. $1 \mathrm{~g}$ ) was thawed at $22^{\circ} \mathrm{C}$ for $4 \mathrm{~h}$, and SSC was assessed using a digital refractometer (ATAGO Model PR-101 $\alpha$, Japan) using the extracted juice following A.O.A.C reference method (AOAC, 1997). SSC ranged from 5.8 to $37.5 \%$ (Table 1 ).

\subsection{Software and data analysis}

The Unscrambler version 10.0.1 (Camo, Oslo, Norway) and Matlab version R2012b (Math-Works, Natick, USA) with the PLStoolbox version 7.5 (Eigenvector Research, Inc., Wenatchee, WA) were used for data analysis. Spectra were pre-processed using either standard normal variate, (SNV); Savitzky-Golay, second polynomial order and second derivative $\left(d^{2} A\right)$ with smoothing window of 15 points $(7+7)$; SNV $+d^{2} A$.

Principal component analysis (PCA) was considered to study the influence of the external variables (local, year, and species). PCA was employed using a random cross-validation method with 25 segments. Partial least squares regression (PLSR) models were developed using different pre-processing and optimized wavelength windows using a random cross-validation method, with 25 segments. The optimal wavelength window for the PLSR model was selected considering: (i) correlations between each wavelength of the spectra and the reference values; (ii) interval partial least squares (iPLS), with intervals of $10-150$ width, using steps described by Norgaard et al. (2000); and (iii) the PLSR wavelength window optimization (Opt_wave) for PLSR model described by

Table 2

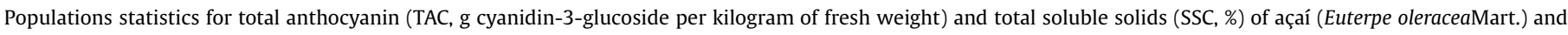
juçara (Euterpe edulisMart.) fruits from different years.

\begin{tabular}{|c|c|c|c|c|c|c|c|}
\hline Species & Year & Population & Sample $(n)$ & $\begin{array}{l}\text { Mean } \\
\text { TAC }\left(\mathrm{g} \mathrm{kg}^{-1}\right)\end{array}$ & S.D. & Minimum & Maximum \\
\hline Açaí (A) & 2012 & A-2012 & 133 & 16.58 & 8.39 & 4.29 & 33.48 \\
\hline Açaí (A) & 2013 & A-2013 & 142 & 21.04 & 11.97 & 0.73 & 43.89 \\
\hline Juçara (J) & 2012 & $\mathrm{~J}-2012$ & 130 & 21.30 & 8.26 & 9.15 & 38.65 \\
\hline Juçara (J) & 2013 & $\mathrm{~J}-2013$ & 100 & 13.21 & 8.16 & 0.10 & 31.27 \\
\hline$A+J$ & 2012 & $A+J-2012$ & 263 & 18.91 & 8.65 & 4.29 & 38.65 \\
\hline$A+J$ & 2013 & $A+J-2013$ & 242 & $\begin{array}{l}17.80 \\
\text { SSC (\%) }\end{array}$ & 11.25 & 0.10 & 43.86 \\
\hline Açaí (A) & 2012 & A-2012 & 133 & 20.77 & 5.09 & 11.36 & 31.86 \\
\hline Açaí (A) & 2013 & A-2013 & 142 & 22.85 & 7.88 & 9.03 & 37.46 \\
\hline Juçara (J) & 2012 & $\mathrm{~J}-2012$ & 130 & 8.34 & 4.73 & 10.88 & 28.94 \\
\hline Juçara (J) & 2013 & $\mathrm{~J}-2013$ & 100 & 14.99 & 5.57 & 5.77 & 26.63 \\
\hline$A+J$ & 2012 & $A+J-2012$ & 263 & 19.57 & 5.06 & 10.88 & 31.86 \\
\hline $\mathrm{A}+\mathrm{J}$ & 2013 & $A+J-2013$ & 242 & 19.60 & 8.01 & 5.77 & 37.46 \\
\hline
\end{tabular}

S.D. = standard deviation 


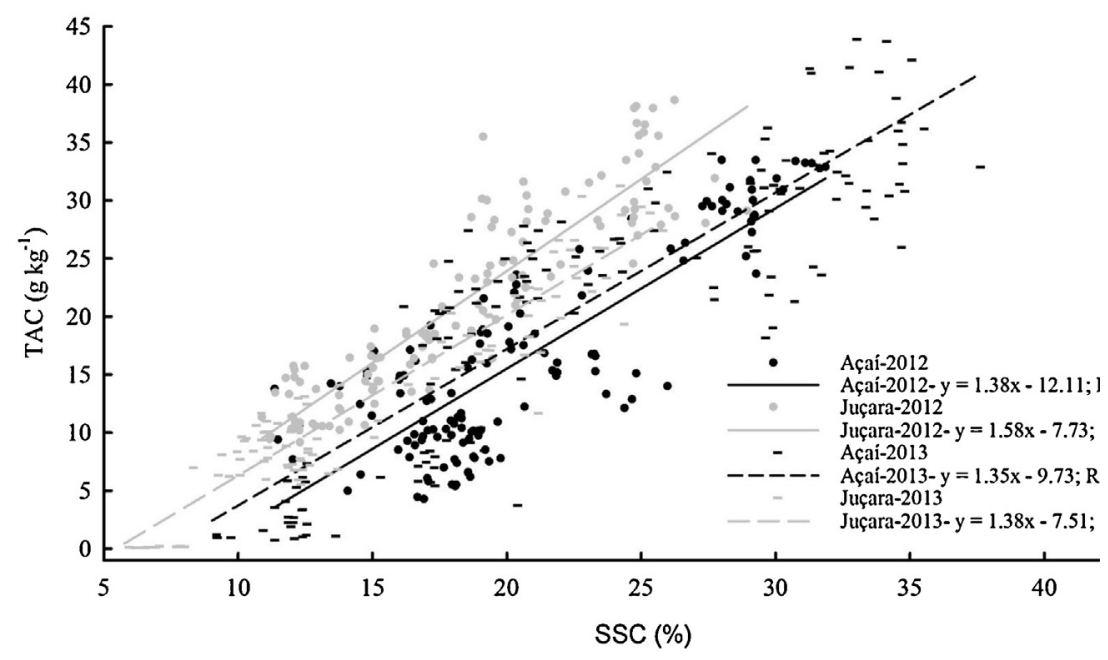

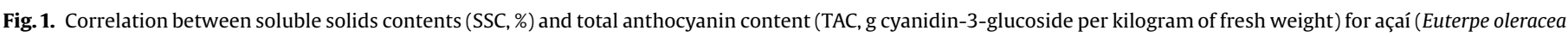
Mart.) and juçara (Euterpe edulis Mart.) fruits.

Guthrie (Guthrie et al., 2005), using $3 \mathrm{~nm}$ wavelength increments. The latter two window optimizations were carried out using Matlab with PLS-toolbox (7.5; Eigenvector, USA). After variable selection, PLSR models were developed using the optimized spectral window with The Unscrambler software.

In these tests, data sets were divided into two groups by year, for each species and for species combined (Table 2). Model performance was described by the statistical terms of coefficient of determination of cross calibration $\left(R_{\text {cv }}^{2}\right)$ and root mean square error of cross validation (RMSE $E_{C V}$ ) and in prediction, coefficient of determination of prediction $\left(R_{\mathrm{p}}^{2}\right)$, bias, root mean square error for prediction $\left(\mathrm{RMSE}_{\mathrm{P}}\right.$ ), bias corrected RMSE $\mathrm{P}_{\mathrm{P}}$ and ratio of the standard deviation of TAC or SSC to bias corrected $\operatorname{RMSE}_{\mathrm{P}}$ (S.D. $R_{\mathrm{p}}$ ) (Golic and Walsh, 2006; Nicolaï et al., 2007). Results were compared using Fearn's criteria at $p 0.05$ (Fearn, 1996).

\section{Results and discussion}

\subsection{SSC and TAC correlation}

SSC and TAC varied from 5.8 to $37.5 \%$ and from 0.1 to $43.6 \mathrm{~g} \mathrm{~kg}^{-1}$, respectively (Table 1 ). The relationship between TAC and SSC varied according to species and years, with $R^{2}$ values varying from 0.70 to 0.89 (Fig. 1). This result infers similar kinetics of accumulation for both attributes during maturation (Rogez et al., 2011).

\subsection{Spectra and PCA}

The overall shape of the absorbance $(\log 1 / R)$ spectra was similar for species, years and locality of harvest, with major information at $1150-1250 \mathrm{~nm}, 1350-1600 \mathrm{~nm}$ and $1950-2150 \mathrm{~nm}$ regions (Fig. 2). Spectral features were interpreted as associated with the $\mathrm{O}-\mathrm{H}$ first overtone region $(1350-1600 \mathrm{~nm})$ and $\mathrm{O}-\mathrm{H}$ combinations $(1950-2150 \mathrm{~nm})$, while the small peak between $1150 \mathrm{~nm}$ and $1250 \mathrm{~nm}$ corresponds to the first overtone of $\mathrm{C}-\mathrm{H}$ combination.

There was noticeable offset between individual spectra (Fig. 2A). On average, juçara fruit showed a higher absorbance reading $(\log 1 / R)$ than açaí fruit (Fig. $2 A)$. The apparent absorption level is a function of the level of specular and diffuse reflection, as well as actual absorption. Juçara fruit has less waxy cuticle (Pessoa and Teixeira, 2012), and fruits are normally smaller (Calvi and PinaRodrigues, 2005) and have higher anthocyanin content (Inácio et al., 2013) than açaí fruit. Given the observed offsets between spectra (Fig. 2A), SNV (Fig. 1B) and SNV $+d^{2} A$ (Fig. 2C) preprocessing techniques (Naes et al., 2002; Nicolaï et al., 2007) were trialled.

PCA analysis was undertaken to gauge the level of spectral variance between population by species, year and location $(n=505)$. The PCA plot developed using absorbance $(\log =1 / R)$ spectra revealed a strong overlap of populations of different seasons, with some separation along the PC-1 axis for species (Fig. 3A). After SNV (Fig. 3B) and SNV $+d^{2} A$ (Fig. 2C) treatments, the separation of species and populations was increased.

The spectral difference between populations (Fig. 3B and C) can be explained as the difference in cultivation conditions, resulting in physiological differences, for example, chemical composition, maturity stage, size, weight, cuticle thickness, etc. (Pessoa and Teixeira, 2012), with resulting impact. Due to the spectral differences of açaí and juçara populations

Dall' Acqua et al. (2015) reported that FT-NIR spectra pretreated with multiplicative scatter correction (MSC) had 98\% correct classification and $97.3 \%$ prediction accuracy in discriminating intact açaí and juçara fruits. As a robust model should contain the maximum variation to be expressed in the prediction sets the development of a separate model may be justified (Golic and Walsh, 2006).

\subsection{Regression models - spectral pre-treatment}

The correlation coefficient of TAC and SSC with absorbance at individual wavelengths (Fig. 4), were higher at wavelengths corresponding to the $\mathrm{C}-\mathrm{H}$ first and second overtone regions, and the $\mathrm{O}-\mathrm{H}$ first overtone region, and the region of $\mathrm{O}-\mathrm{H}$ combinations. Cozzolino et al. (2004) suggested that the weighting around $2300 \mathrm{~nm}$ corresponds to $\mathrm{CH}$-stretch and $\mathrm{CH}$-combinations consistent with phenolic compounds that could relate to anthocyanin content. The correlation coefficient weights were similar for TAC and SSC, which is consistent with a correlation between the two variables.

However, for correlation between absorbance at a single wavelength and attribute level, higher correlation coefficients were obtained for TAC content than SSC (Fig. 4A). A similar result pertained to PLSR models, both in calibration and prediction (Tables 3 and 5). This result may be due to the use of reflectance optics in the FT-NIR which gathers surface $(<4 \mathrm{~mm})$ information of intact fruit (Lammertyn et al., 2000; Nicolaï et al., 2007), as 


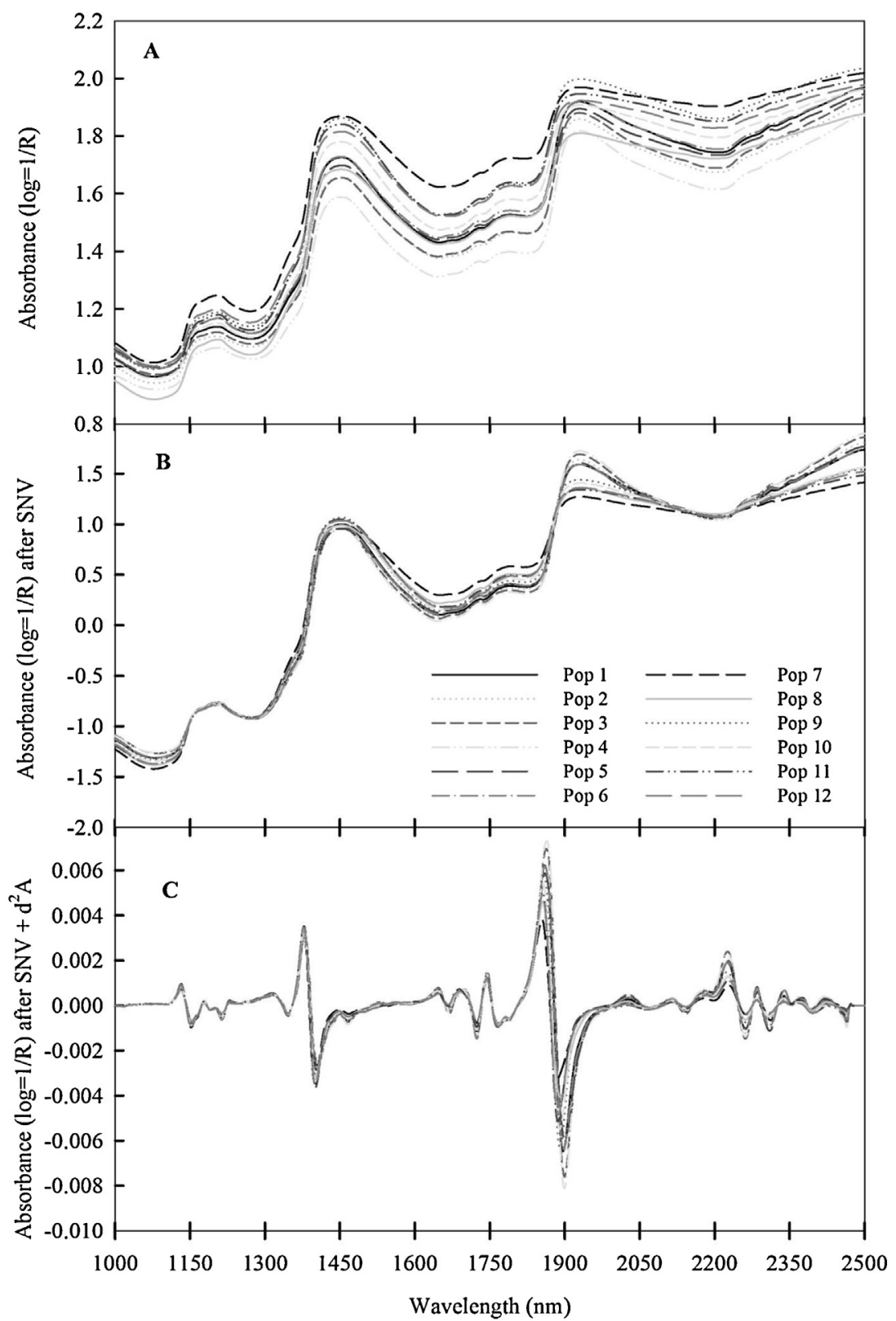

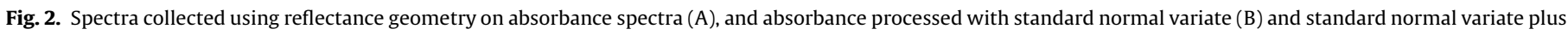
Savitzky-Golay second derivative (C) for the average spectra of 12 populations of fruit.

anthocyanin content is higher in the exocarp than the mesocarp while SSC is primarily in the mesocarp.

With the application of SNV pre-processing to raw spectra, the correlation of spectra at any given wavelength with TAC and SSC was improved, particularly for açaí fruit (Fig. 4B). This result is consistent with more variation in the amount of light scattering (e.g. due to cuticle variation) in açaí than juçara fruit (Fig. 4). In SNV plus derivative treated data, information was present in many wavelength regions (Fig. 4C).

Test of pre-processing option were performed with different sample sets grouped by year, using the 2012 sample set as the calibration set and the 2013 sample set as the prediction set (Table 2). PLSR models were developed individually for açaí and juçara, and also for both species combined. TAC PLSR calibration models obtained for individual species were better than for models based on the combination of two species (Table 3). The PLSR models for TAC for açaí and both species combined were neither improved by using SNV or SNV $+d^{2} A$ pre-treatments over use of raw spectra, in terms of calibration parameters, however accuracy of prediction was improved for açaí fruit TAC model, with significative decrease in bias value to -1.16 for $\mathrm{SNV}+d^{2} A$ treated spectra (Table 3 ). Juçara model for TAC was not improved by using pre-processing (Table 3 ).

The use of SNV $+d^{2} A$ to pre-process spectra improved the SSC PLSR models statistics compared to use of raw spectra in terms of

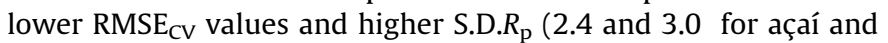
both species combined, respectively), with use of fewer PCs (6 for açaí and both species combined, respectively, Table 3 ). As a result, $\mathrm{SNV}+d^{2} A$ was chosen as the standard pre-processing option for model development for açaí and both species combined. However, when Juçara model was built using $\mathrm{SNV}+d^{2} A$ spectra showed higher RMSE $\mathrm{CV}_{\mathrm{C}}(1.7 \%)$ and similar S.D. $R_{\mathrm{p}}(2.1)$ compared to use raw spectra (1.6\% and 2.1 for RMSE $\mathrm{CV}_{\mathrm{CV}}$ and S.D. $R_{\mathrm{p}}$, respectively, Table 3 ), thereby the raw spectra (nil) was chosen. 

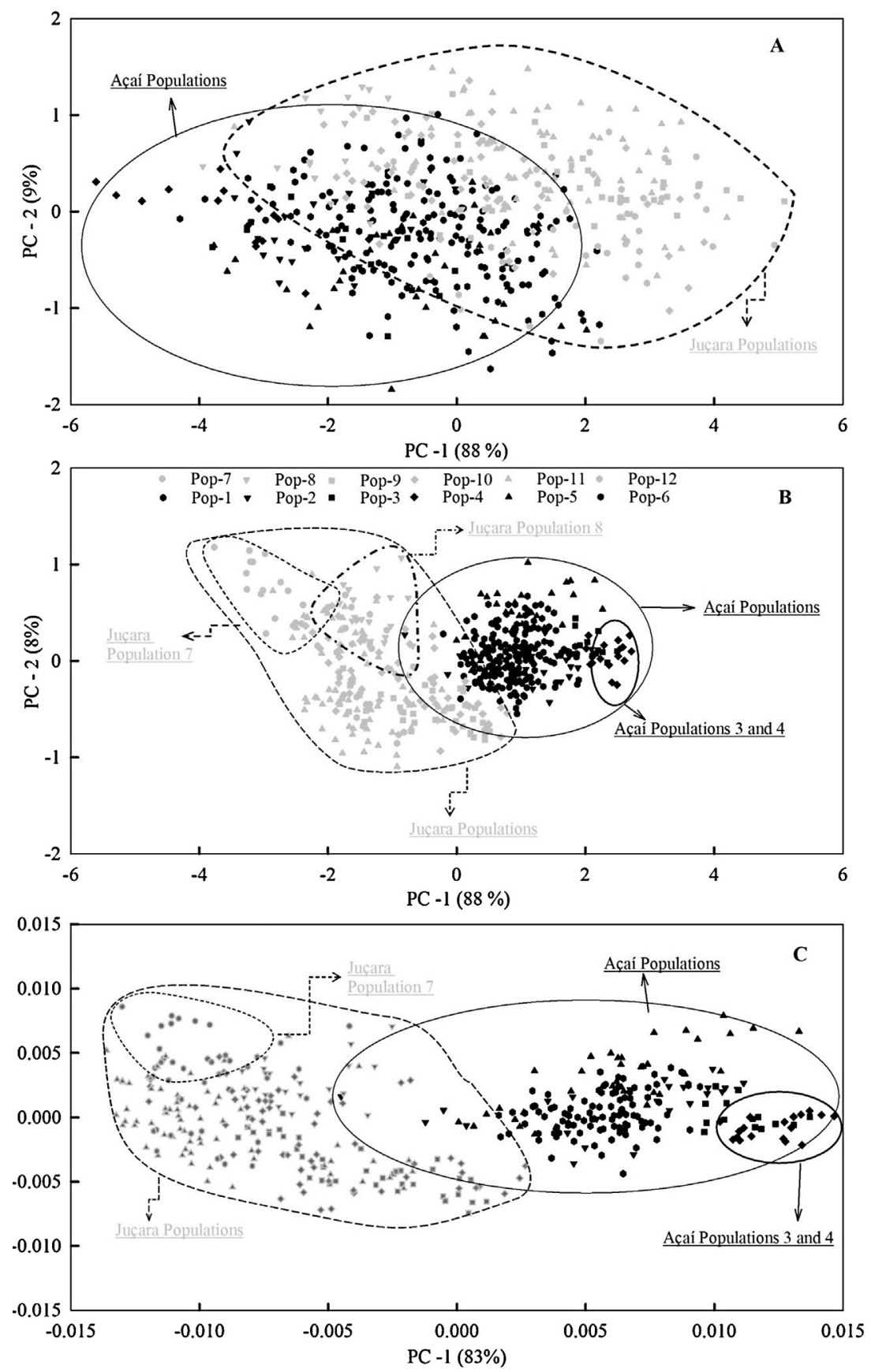

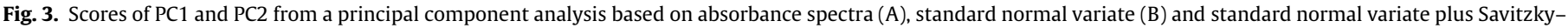
Golay second derivative (C) for a combined set of data (populations 1-12).

\subsection{Regression models - wavelength weighting}

Tests of wavelength window option were performed with the same data sets used in the pre-processing (Table 2). Three method of spectral window selection were trialled, with the best result for açaí fruit achieved a wavelength range based on the correlation between the absorbance at individual wavelengths and TAC (1606-1793 nm, Table 4). The best PLSR model for TAC prediction in juçara fruit was developed using two spectral windows (10861189 and $1562-2079 \mathrm{~nm}$ ) from raw spectra selected using the iPLS method (Table 4). The best PLSR model for TAC for both species combined was based on the wavelength region $(1081-1678 \mathrm{~nm}$, Fig. 5A) selected using the method of Guthrie (Guthrie et al., $2005)$. The best performance in terms of S.D. $R_{\mathrm{p}}$ was achieved for açaí (3.0), juçara (2.6) and both species combined (2.2) TAC PLSR models.

Inácio et al. (2013) reported TAC models with $\mathrm{RMSE}_{\mathrm{P}}$ of $4.8 \mathrm{~g} \mathrm{~kg}^{-1}$ (S.D. $=14.8 \mathrm{~g} \mathrm{~kg}^{-1}$ ) for both species combined, compared to the RMSE of $5.92 \mathrm{~g} \mathrm{~kg}^{-1}$ (S.D. $=11.25 \mathrm{~g} \mathrm{~kg}^{-1}$ ) achieved in the current study. However, the former study involved prediction of a set of fruit selected to represent the calibration set (i.e. calibration and validation sets were drawn from the same population), whereas in the current study a truly independent prediction set was used. In this regard, the current results are more realistic and accurate fulfilling what is expected in practical use. Interestingly, the RMSEP for the açaí TAC PLSR model was lower than the value reported by Inácio et al. (2013), 4.0 and $4.8 \mathrm{~g} \mathrm{~kg}^{-1}$, respectively, and S.D. of 11.97 and $14.8 \mathrm{~g} \mathrm{~kg}^{-1}$, respectively. 


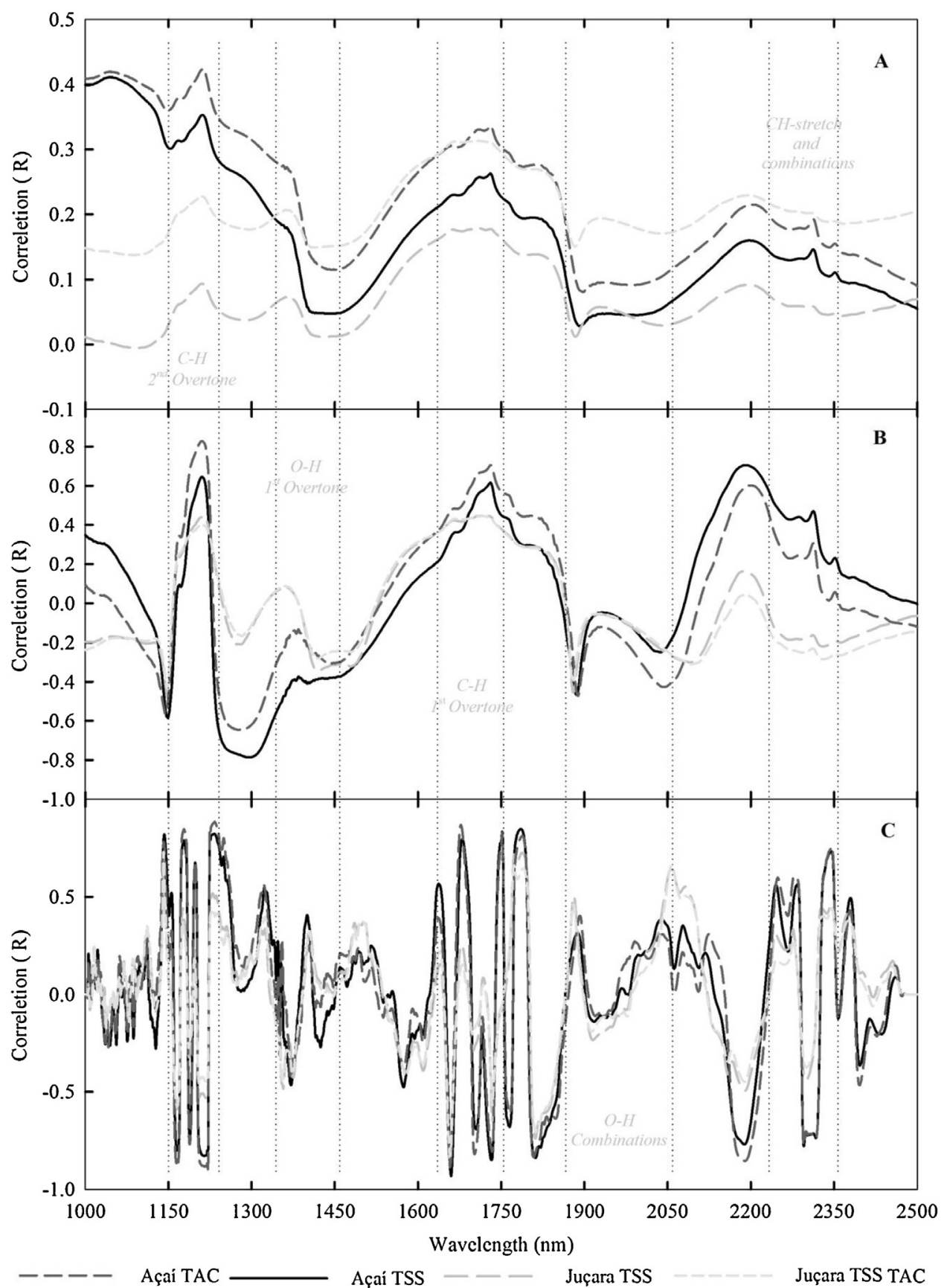

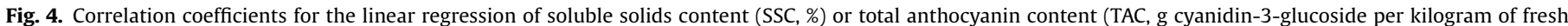

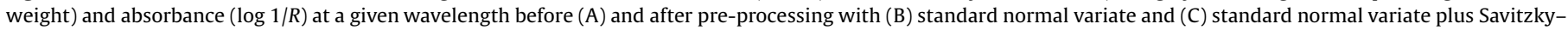
Golay second derivative for açaí (Euterpe oleracea Mart.) and juçara (Euterpe edulis Mart.) fruits.

Using the spectral window optimization procedure reported by Guthrie et al. (2005), the region 1629-1923 nm was chosen for PLSR SSC model using juçara fruits (Fig. 5B) and the $1220-2399 \mathrm{~nm}$ for PLSR SSC model using both species combined (Fig. 5C), with RMSE $\mathrm{P}_{\mathrm{P}}$ values of $2.64 \%$ and $2.75 \%$, respectively (Table 4). For SSC prediction in açaí fruit the best PLSR model was developed using the spectral window of 1640$1738 \mathrm{~nm}$, with a $R_{\mathrm{p}}^{2}$ of 0.90 and RMSE $\mathrm{P}_{\mathrm{P}}$ of $2.55 \%$ (Table 4 ). The best models for SSC prediction in both species combined fruit and açaí fruit achieved $R_{\mathrm{p}}^{2}$ of 0.91 and 0.90 , respectively (Table 4).

\subsection{Regression models - robustness test}

The robustness of the TAC models was tested by dividing the data set based on species, locality and years of harvest (Table 1). The PLSR models were built by adding spectra to calibration sets for açaí models starting from of Pop-1 and ending at Pop 1-5; for juçara models starting from Pop 7 until Pop 7-11, and for both species combined two calibrations sets Pop 1-2+7-8 and Pop 1$2+5-8+11-12$ were used (Table 1 ). For validation purpose only one data set was used; Pop- 6 for açaí, Pop 12 for juçara and Pop $3+4+9+10$ for both species combined models (Table 1 ). 
Table 3

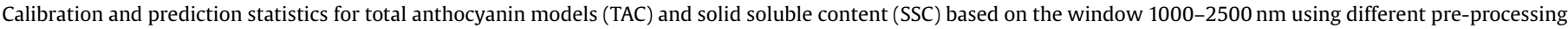
options, for populations of açaí (Euterpe oleracea Mart.) and juçara (Euterpe edulis Mart.) fruits described in Table 2.

\begin{tabular}{|c|c|c|c|c|c|c|c|c|c|c|}
\hline Variable & $\begin{array}{l}\text { Calibration } \\
\text { Population }\end{array}$ & Pre-processing & PC & $R_{\mathrm{cv}}^{2}$ & $\mathrm{RMSE}_{\mathrm{CV}}$ & $\begin{array}{l}\text { Prediction } \\
\text { Population }\end{array}$ & $R_{\mathrm{p}}^{2}$ & RMSEP & Bias & ${ }^{\mathrm{a}} \mathrm{S} . \mathrm{D} \cdot \boldsymbol{R}_{\mathrm{p}}$ \\
\hline \multirow{9}{*}{$\begin{array}{l}\text { TAC } \\
\qquad\left(\mathrm{g} \mathrm{kg}^{-1}\right)\end{array}$} & & nil & 9 & 0.92 & 2.46 & & 0.87 & 5.83 & -2.26 & 2.23 \\
\hline & A-2012 & SNV & 7 & 0.90 & 2.62 & A-2013 & 0.87 & $5.75^{\mathrm{ns}}$ & $-2.45^{\mathrm{ns}}$ & 2.30 \\
\hline & & $\mathrm{SNV}+d^{2} A$ & 7 & 0.92 & 2.39 & & 0.88 & $5.09^{\mathrm{ns}}$ & $-1.16^{\text {sig }}$ & 2.42 \\
\hline & & nil & 9 & 0.91 & 2.51 & & 0.87 & 9.54 & 8.87 & 2.32 \\
\hline & $\mathrm{J}-2012$ & SNV & 7 & 0.89 & 2.77 & $\mathrm{~J}-2013$ & 0.82 & $9.36^{\mathrm{ns}}$ & $8.64^{\mathrm{ns}}$ & 2.27 \\
\hline & & $\mathrm{SNV}+d^{2} A$ & 6 & 0.90 & 2.62 & & 0.87 & $8.72^{\text {ns }}$ & $7.86^{\mathrm{ns}}$ & 2.17 \\
\hline & & nil & 11 & 0.89 & 2.91 & & 0.69 & $6.76 \mathrm{st}$ & $1.96 \mathrm{st}$ & 1.74 \\
\hline & $A+J-2012$ & SNV & 10 & 0.88 & 3.00 & $A+J-2013$ & 0.74 & $5.92^{\text {ns }}$ & $1.00^{\mathrm{ns}}$ & 1.93 \\
\hline & & $\mathrm{SNV}+d^{2} A$ & 8 & 0.89 & 2.90 & & 0.70 & $6.50^{\mathrm{ns}}$ & $2.00^{\mathrm{ns}}$ & 1.82 \\
\hline \multirow{9}{*}{$\begin{array}{l}\text { SSC } \\
\qquad(\% \mathrm{w} / \mathrm{v})\end{array}$} & & Nil & 6 & 0.86 & 1.94 & & 0.84 & 3.73 & -0.25 & 2.12 \\
\hline & A-2012 & SNV & 4 & 0.87 & 1.87 & A-2013 & 0.84 & $3.74^{\mathrm{ns}}$ & $-0.63^{\mathrm{ns}}$ & 2.14 \\
\hline & & $\mathrm{SNV}+d^{2} A$ & 6 & 0.89 & 1.75 & & 0.87 & $3.38^{\text {sig }}$ & $0.86^{\mathrm{ns}}$ & 2.41 \\
\hline & & Nil & 9 & 0.89 & 1.59 & & 0.78 & 4.45 & 3.36 & 2.08 \\
\hline & $\mathrm{J}-2012$ & SNV & 8 & 0.90 & 1.51 & $\mathrm{~J}-2013$ & 0.74 & $4.20^{\mathrm{ns}}$ & $2.88^{\mathrm{ns}}$ & 1.82 \\
\hline & & $\mathrm{SNV}+d^{2} A$ & 4 & 0.87 & 1.74 & & 0.81 & $4.18^{\mathrm{ns}}$ & $3.28^{\mathrm{ns}}$ & 2.11 \\
\hline & & Nil & 10 & 0.87 & 1.84 & & 0.88 & 3.41 & 1.81 & 2.77 \\
\hline & $A+J-2012$ & SNV & 9 & 0.88 & 1.79 & $A+J-2013$ & 0.90 & $3.22^{\mathrm{ns}}$ & $1.88^{\text {ns }}$ & 3.06 \\
\hline & & $\mathrm{SNV}+d^{2} A$ & 6 & 0.88 & 1.79 & & 0.88 & $3.36^{\text {ns }}$ & $1.93^{\mathrm{ns}}$ & 2.91 \\
\hline
\end{tabular}

${ }^{\mathrm{ns}} \mathrm{RMSEP}$ or Bias is not significantly $(P>0.95)$ different to the nil pre-processing result for each variable;

${ }^{\text {sig }}$ RMSEP or Bias is significantly $(P>0.95)$ different to the nil pre-processing result for each variable;

a ratio of the standard deviation of TAC or SSC to bias corrected RMSEP.

Table 4

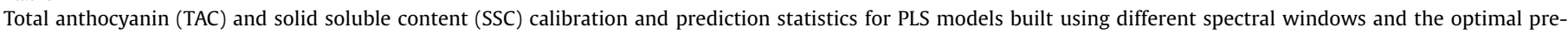
processing option identified in Table 3, for açaí (Euterpe oleracea Mart.) and juçara (Euterpe edulis Mart.) fruits.

\begin{tabular}{|c|c|c|c|c|c|c|c|c|c|c|c|}
\hline \multirow[b]{2}{*}{ Variable } & \multicolumn{6}{|l|}{ Calibration } & \multicolumn{5}{|l|}{ Prediction } \\
\hline & Population & processing & Wavelength (nm) & PC & $\mathrm{R}_{\mathrm{cv}}^{2}$ & $\mathrm{RMSE}_{\mathrm{CV}}$ & Population & $R_{\mathrm{p}}^{2}$ & RMSEP & Bias & ${ }^{\mathrm{g}} \mathrm{S} . \mathrm{D} . R_{\mathrm{p}}$ \\
\hline \multirow{12}{*}{$\begin{array}{l}\text { TAC } \\
\qquad\left(\mathrm{g} \mathrm{kg}^{-1}\right)\end{array}$} & A-2012 & $\mathrm{SNV}+d^{2} A$ & $1000-2500$ & 7 & 0.92 & 2.39 & A-2013 & 0.88 & 5.09 & -1.16 & 2.42 \\
\hline & & & \#1606-1793 & 4 & 0.91 & 2.50 & & 0.90 & $3.99^{\text {sig }}$ & $0.46^{\mathrm{ns}}$ & 3.02 \\
\hline & & & aiPLS-8seg. & 11 & 0.93 & 2.17 & & 0.89 & $4.37^{\mathrm{ns}}$ & $-1.18^{\mathrm{ns}}$ & 2.84 \\
\hline & & & \#\#1351-1689 & 5 & 0.89 & 2.80 & & 0.86 & $5.16^{\mathrm{ns}}$ & $-1.93^{\mathrm{ns}}$ & 2.50 \\
\hline & $\mathrm{J}-2012$ & Nil & $1000-2500$ & 9 & 0.91 & 2.51 & $\mathrm{~J}-2013$ & 0.86 & 9.54 & 8.87 & 2.32 \\
\hline & & & ${ }^{\#} 1606-1793$ & 7 & 0.88 & 2.85 & & 0.84 & $8.56^{\mathrm{ns}}$ & $7.80^{\mathrm{ns}}$ & 2.32 \\
\hline & & & biPLS-2seg. & 15 & 0.92 & 2.40 & & 0.87 & $7.68^{\mathrm{ns}}$ & $7.00^{\mathrm{ns}}$ & 2.58 \\
\hline & & & \#\#1625-2049 & 11 & 0.91 & 2.50 & & 0.87 & $8.42^{\mathrm{ns}}$ & $7.75^{\mathrm{ns}}$ & 2.48 \\
\hline & $A+J-2012$ & SNV & $1000-2500$ & 10 & 0.88 & 3.00 & $A+J-2013$ & 0.74 & 5.92 & 1.00 & 1.93 \\
\hline & & & ${ }^{\#} 1606-1793$ & 8 & 0.89 & 2.91 & & 0.66 & $6.83^{\mathrm{ns}}$ & $1.69^{\mathrm{ns}}$ & 1.70 \\
\hline & & & ciPLS-8seg. & 16 & 0.92 & 2.42 & & 0.70 & $6.21^{\mathrm{ns}}$ & $0.25^{\mathrm{ns}}$ & 1.81 \\
\hline & & & \#\#1081-1678 & 7 & 0.86 & 2.87 & & 0.79 & $5.43^{\text {ns }}$ & $1.54^{\mathrm{ns}}$ & 2.16 \\
\hline \multirow{12}{*}{$\begin{array}{l}\text { SSC } \\
\qquad(\% w / v)\end{array}$} & A-2012 & $\mathrm{SNV}+d^{2} A$ & $1000-2500$ & 6 & 0.89 & 1.75 & A-2013 & 0.87 & 3.38 & 0.86 & 2.41 \\
\hline & & & ${ }^{\#} 1640-1738$ & 4 & 0.90 & 1.74 & & 0.90 & 2.55 & 0.22 & 3.10 \\
\hline & & & diPLS-5seg & 4 & 0.90 & 1.65 & & 0.85 & $3.21^{\mathrm{ns}}$ & $0.53^{\mathrm{ns}}$ & 2.49 \\
\hline & & & \#\#1570-1785 & 4 & 0.88 & 1.80 & & 0.88 & $2.90^{\mathrm{ns}}$ & $0.61^{\mathrm{ns}}$ & 2.86 \\
\hline & $\mathrm{J}-2012$ & Nil & $1000-2500$ & 9 & 0.89 & 1.59 & $\mathrm{~J}-2013$ & 0.78 & 4.45 & 3.36 & 2.08 \\
\hline & & & ${ }^{\#} 1474-1860$ & 9 & 0.87 & 1.73 & & 0.87 & $2.94^{\text {sig }}$ & $2.11^{\mathrm{ns}}$ & 2.71 \\
\hline & & & eiPLS-4seg & 9 & 0.86 & 1.89 & & 0.80 & $4.26^{\mathrm{ns}}$ & $2.86^{\mathrm{ns}}$ & 1.77 \\
\hline & & & \#\# 1629-1923 & 10 & 0.87 & 1.68 & & 0.87 & $2.64^{\text {sig }}$ & $1.67^{\mathrm{ns}}$ & 2.72 \\
\hline & $A+J-2012$ & $\mathrm{SNV}+d^{2} A$ & $1000-2500$ & 6 & 0.88 & 1.79 & $A+J-2013$ & 0.89 & 3.36 & 1.93 & 2.91 \\
\hline & & & ${ }^{\#} 1125-2276$ & 8 & 0.88 & 1.73 & & 0.89 & $3.00^{\mathrm{ns}}$ & $1.34^{\mathrm{ns}}$ & 2.98 \\
\hline & & & ${ }^{f}$ iPLS-5seg & 10 & 0.87 & 1.80 & & 0.91 & $2.77^{\mathrm{ns}}$ & $1.14^{\mathrm{ns}}$ & 3.18 \\
\hline & & & \#\#1220-2399 & 9 & 0.89 & 1.72 & & 0.91 & $2.75^{\text {sig }}$ & $1.30^{\mathrm{ns}}$ & 3.30 \\
\hline
\end{tabular}

\footnotetext{
\#- selected considering correlations between each wavelength of the spectra and the reference values;

\#\# Wavelength selected by Opt_wave;

${ }^{n}$ RMSEP or Bias is not significantly $(P>0.95)$ different to the nil pre-processing result for each variable;

${ }^{\text {sig }}$ RMSEP or Bias is significantly $(P>0.95)$ different to the nil pre-processing result for each variable;

a $1136-1156+1358-1372+1644-1664+1689-1709+1736-1758+1785-1808+1865-1891+2016-2045+2118-2151$ mm selected by iPLS;

b $1086-1189+1562-2079 \mathrm{~mm}$ selected by iPLS;

c $1063-1086+1111-1189+1219-1280+1315-1387+1470-1721+1851-1920+2000-2079+2173-2268$ mm selected by iPLS;

d $1225-1236+1488-1504+1602-1621+1644-1664+1712-1758 \mathrm{~mm}$ selected by iPLS;

e $1033-1049+1086-1125+1623-1709+1760-1862 \mathrm{~mm}$ selected by iPLS;

f $1041-1086+1136-1189+1388-1468+1562-1920+2272-2465 \mathrm{~mm}$ selected by iPLS;

$\mathrm{g}$ ratio of the standard deviation of TAC or SSC to bias corrected RMSEP.
} 
Table 5

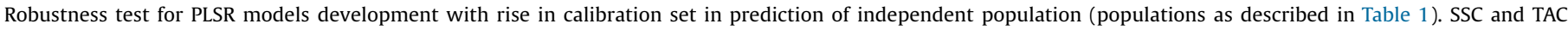

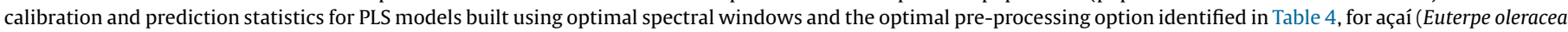
Mart.) and juçara (Euterpe edulis Mart.) fruits .

\begin{tabular}{|c|c|c|c|c|c|c|c|c|c|}
\hline \multicolumn{7}{|l|}{ Calibration } & \multicolumn{3}{|l|}{ Prediction } \\
\hline Variable & Specie & Populations & Processing & Wave $(\mathrm{nm})$ & $R_{\mathrm{cv}}^{2}$ & RMSE $_{\mathrm{CV}}$ & Populations & $R_{\mathrm{p}}^{2}$ & ${ }^{\mathrm{a}} \mathrm{SEP}$ \\
\hline \multirow{12}{*}{$\begin{array}{l}\text { TAC } \\
\quad\left(\mathrm{g} \mathrm{kg}^{-1}\right)\end{array}$} & Açaí & Pop 1 & $\mathrm{SNV}+d^{2} A$ & 1606-1793 & 0.69 & 2.22 & Pop6 & 0.40 & 5.59 \\
\hline & & Pop 1-2 & & & 0.78 & 2.38 & & 0.69 & 4.58 \\
\hline & & Pop 1-3 & & & 0.80 & 2.32 & & 0.66 & 4.52 \\
\hline & & Pop $1-4$ & & & 0.80 & 2.21 & & 0.68 & 3.79 \\
\hline & & Pop $1-5$ & & & 0.92 & 2.49 & & 0.73 & 3.63 \\
\hline & Juçara & Pop 7 & Nil & $\begin{array}{l}1086-1189+ \\
1562-2079\end{array}$ & 0.84 & 1.77 & Pop 12 & 0.85 & 1.94 \\
\hline & & Pop 7-8 & & & 0.78 & 3.50 & & 0.70 & 2.73 \\
\hline & & Pop 7-9 & & & 0.77 & 3.54 & & 0.28 & 4.88 \\
\hline & & Pop 7-10 & & & 0.87 & 3.18 & & 0.72 & 2.70 \\
\hline & & Pop 7-11 & & & 0.85 & 3.29 & & 0.46 & 3.67 \\
\hline & Combined & Pop $1-2+7-8$ & SNV & $1081-1678$ & 0.93 & 2.60 & Pop 3-4+9-10 & 0.32 & 7.85 \\
\hline & & Pop $1-2+5-8+11-12$ & & & 0.89 & 3.45 & & 0.53 & 5.69 \\
\hline \multirow{12}{*}{$\begin{array}{l}\text { SSC } \\
\qquad(\% w / v)\end{array}$} & Açaí & Pop1 & $\mathrm{SNV}+d^{2} A$ & $1640-1738$ & 0.34 & 1.63 & Pop 6 & 0,76 & 4,11 \\
\hline & & Pop 1-2 & & & 0.70 & 1.63 & & 0.78 & 3.45 \\
\hline & & Pop 1-3 & & & 0.81 & 1.62 & & 0.76 & 3.45 \\
\hline & & Pop $1-4$ & & & 0.74 & 1.76 & & 0.78 & 2.92 \\
\hline & & Pop $1-5$ & & & 0.91 & 1.79 & & 0.79 & 2.87 \\
\hline & Juçara & Pop 7 & Nil & 1629-1923 & 0.61 & 1.70 & Pop 12 & 0.78 & 1.31 \\
\hline & & Pop7-8 & & & 0.43 & 1.71 & & 0.86 & 1.07 \\
\hline & & Pop 7-9 & & & 0.85 & 1.55 & & 0.79 & 1.63 \\
\hline & & Pop 7-10 & & & 0.89 & 1.69 & & 0.86 & 1.03 \\
\hline & & Pop 7-11 & & & 0.82 & 2.15 & & 0.87 & 1.10 \\
\hline & Combined & Pop $1-2+7-8$ & $\mathrm{SNV}+d^{2} A$ & $1220-2399$ & 0.84 & 1.55 & Pop 3-4+9-10 & 0.69 & 2.62 \\
\hline & & Pop $1-2+5-8+11-12$ & & & 0.91 & 2.11 & & 0.80 & 2.33 \\
\hline
\end{tabular}

a SEP- bias corrected RMSEP.

Açaí TAC models based on SNV $+d^{2} A$ spectra over the $1606-$ $1793 \mathrm{~nm}$ region demonstrated better $R_{\mathrm{cv}}^{2}(0.69-0.92), R_{\mathrm{p}}^{2}(0.40-$ 0.73 ) and bias-corrected $\operatorname{RMSE}_{\mathrm{P}}\left(5.6-3.6 \mathrm{~g} \mathrm{~kg}^{-1}\right)$ as the calibration set was expanded (result for Pop 1 and Pop 1-5, respectively). Juçara TAC models constructed using two spectral windows (10861189 plus $1562-2079 \mathrm{~nm}$ ) and raw spectra (absorbance) did not perform as good as the açaí models (Table 5 ). The combined species TAC model based on SNV spectra over the 1081-1678 $\mathrm{nm}$ region had the bias-corrected RMSE $E_{P}$ value $\left(5.7 \mathrm{~g} \mathrm{~kg}^{-1}\right)$ was higher than for açaí (3.6 $\left.\mathrm{g} \mathrm{kg}^{-1}\right)$ and juçara species $\left(4.9 \mathrm{~g} \mathrm{~kg}^{-1}\right.$, Table 5$)$.

The $R^{2}{ }_{\text {cv }}$ on TAC $(0.9,0.8$ and 0.9 for açaí, juçara and both species combined, respectively) are better than the values reported by Cozzolino et al. (2004) for estimation of TAC of intact grapes based on $400-1100 \mathrm{~nm}$ spectra $\left(R_{\mathrm{cv}}^{2} 0.3-0.5\right.$, for population S.D. of $250 \mathrm{mg} \mathrm{kg}^{-1}$ ). The $R^{2}$ represents the proportion of explained variance by the model from the calibration set (Nicolai et al., 2007), as our data set has higher values of standard deviation on TAC than the grapes, this might explain the difference in the $R^{2}$ cv.

The TAC RMSE ${ }_{\mathrm{CV}}$ values $\left(2.5,3.3\right.$ and $3.5 \mathrm{~g} \mathrm{~kg}^{-1}$ for açaí, juçara and both species combined, respectively) are lower than the values reported by Inácio et al. (2013) who reported values of 9.3$21.3 \mathrm{~g} \mathrm{~kg}^{-1}$, for açaí and juçara combined, S.D. of $20.8 \mathrm{~g} \mathrm{~kg}^{-1}$. However, the bias-corrected RMSE ( 7.85 and $5.69 \mathrm{~g} \mathrm{~kg}^{-1} \mathrm{TAC}$ ) values from both species combined were higher than those reported by Inácio (Inácio et al., 2013), $4.8 \mathrm{~g} \mathrm{~kg}^{-1}$ TAC. As Inácio et al. (2013) used only one data set divided into calibration and validation sets, it is not a good indicator of prediction performance as it was not tested with an external set (Golic and Walsh, 2006).

Robustness for SSC was assessed using the same population structures used for TAC (Table 1). For açaí fruit, the SSC model developed using the spectral window 1640-1738 nm and SNV + $d^{2} A$ showed better predicting accuracy when all populations were added to the calibration set (Table 5$)$. It was observed an increase in $R_{\text {cv }}^{2}(034-0.91), R_{\text {MSE }}(1.63-1.79 \%), R_{\mathrm{p}}^{2}(0.76-0.79)$, and decrease in bias-corrected $\mathrm{RMSE}_{\mathrm{P}}(4.14-2.87 \%)$. The same trend was verified in SSC model developed for both species combined, which means the use of SNV $+d^{2} A$ and $1220-2399 \mathrm{~nm}$ window, with the model showing $R^{2}{ }_{\mathrm{cv}}$ of $0.84-0.91$, RMSE $\mathrm{CV}_{\mathrm{CV}} 1.55-2.11 \%, R_{\mathrm{p}}^{2}$ from 0.69 to 0.80 and bias-corrected RMSE of $2.62-2.33 \%$ (Table 5 ). PLSR SSC in juçara fruit with increased the number of sample on calibration set showed inconstancy in calibration and prediction in terms statistics (Table 5). The models for TAC and SSC developed to juçara fruit were worse when the Pop 9 and Pop 11 was added into the calibration set (Table 5). The 9 and 11 populations were harvested on March of 2012 (Table 1) on summer (November and December at 2011 plus January and February at 2012) that happened in an unusual dry summer in this region (I.A.G., 2012). As juçara fruit needs 180 days to mature (Calvi and Pina-Rodrigues, 2005; Pessoa and Teixeira, 2012) these fruits were grown in water stress conditions. Such climate change might have affected açaí and juçara physiological behavior (Pessoa and Teixeira, 2012; Rogez et al., 2011), and it might have changed the spectra information in this particular data set.

The SSC PLSR model for açaí fruit using all samples on calibration set presented $R^{2}{ }_{\mathrm{cv}}$ of $0.91, \mathrm{RMSE}_{\mathrm{CV}}$ of $1.79 \%, R_{\mathrm{p}}^{2}$ of 0.79 and bias-corrected RMSEP of $2.87 \%$. The bias-corrected RMSE values for three PLSR SSC models (açaí, juçara and both species combined) were not as good as those reported for other fruit e.g. mango (Saranwong et al., 2001), peach and nectarine (Golic and Walsh, 2006), but açaí and juçara are native species and there isn't any cultivated variety and/or clones as in other fruit species. 
A)

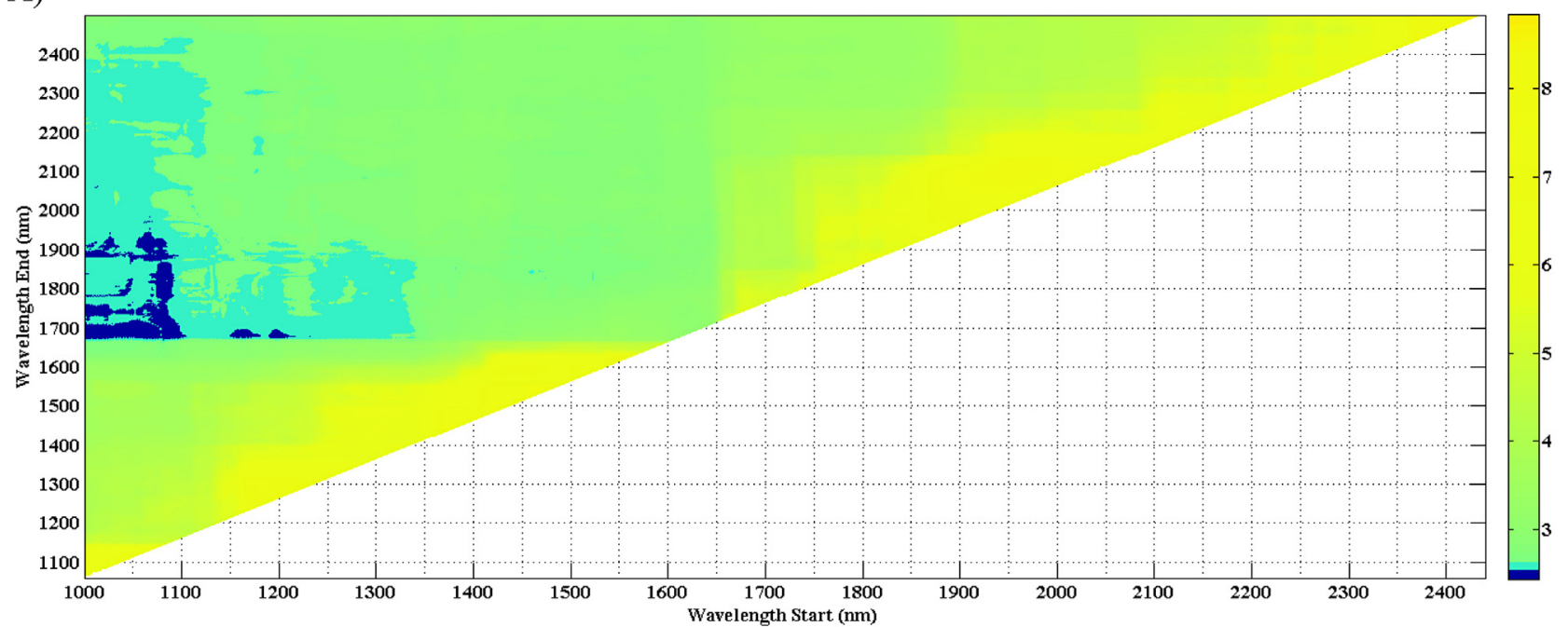

B)

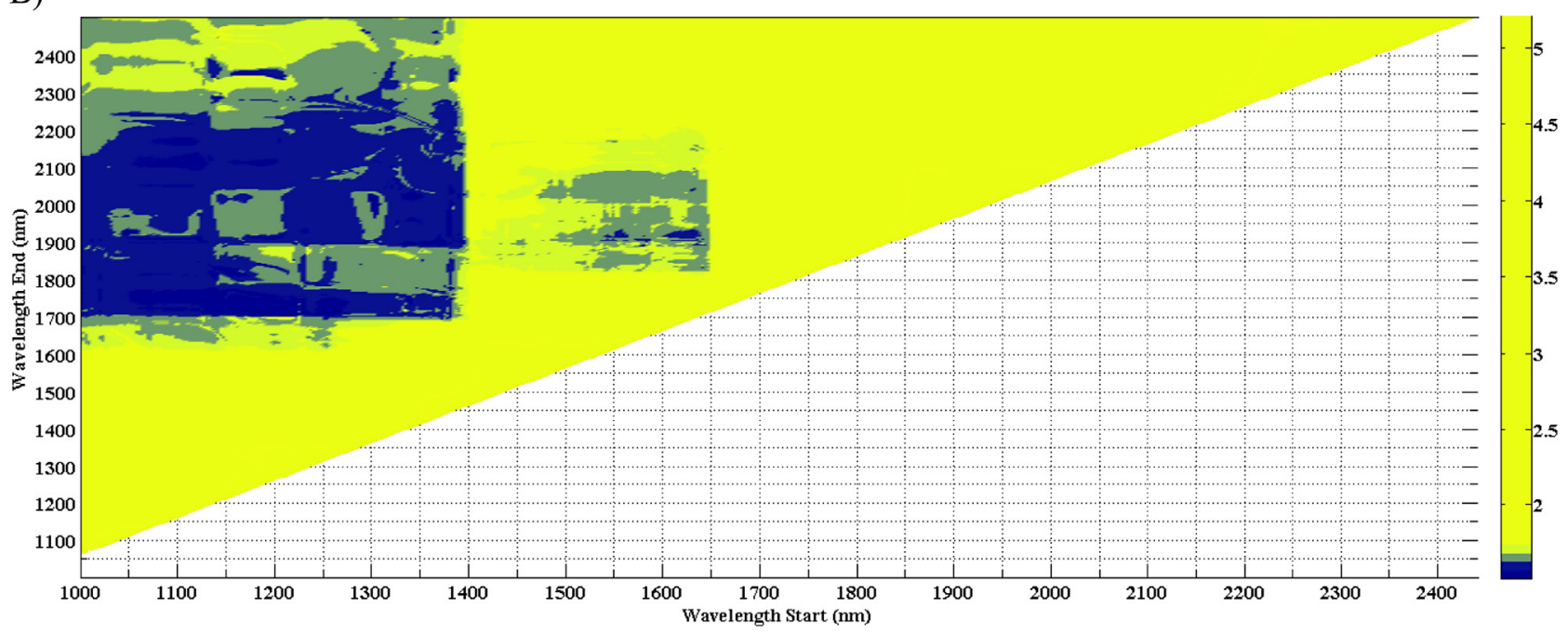

C)

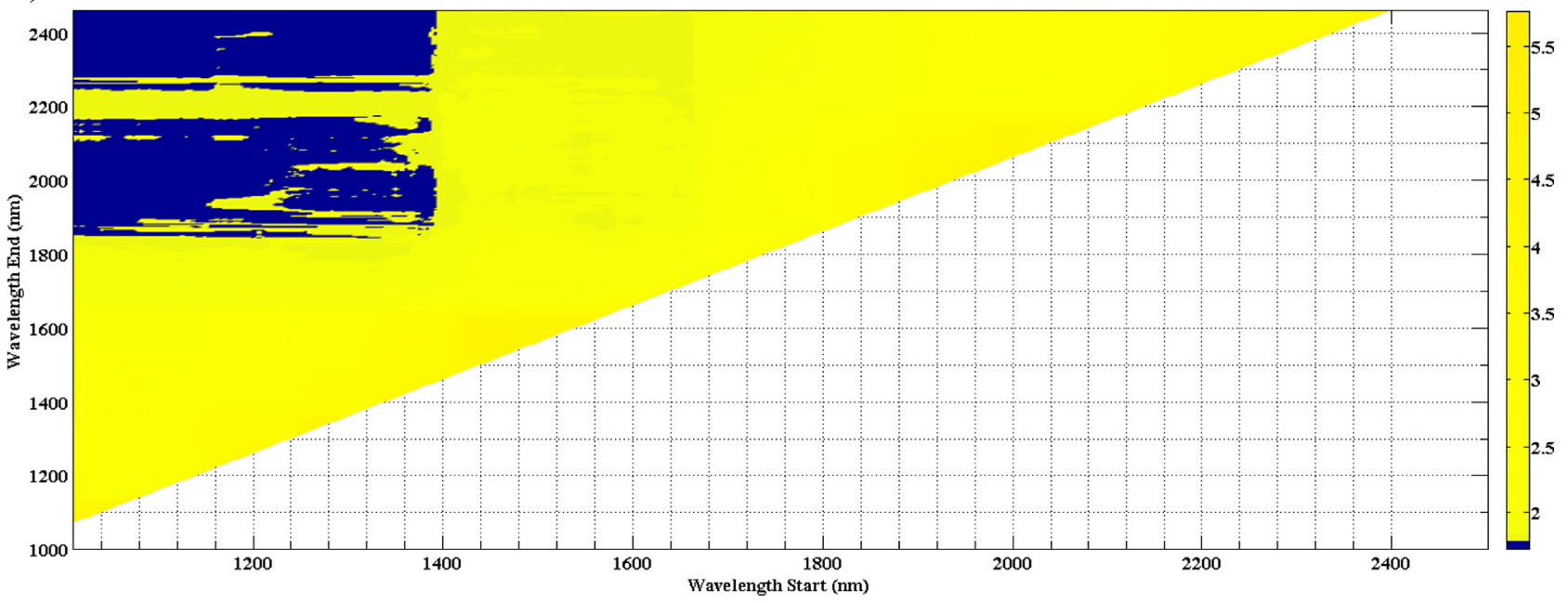

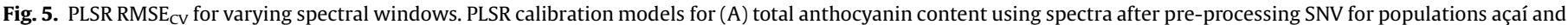

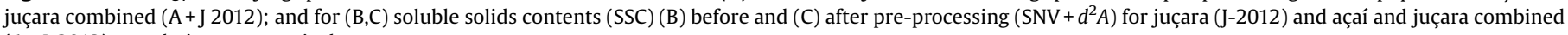
$(\mathrm{A}+\mathrm{J}-2012)$ populations, respectively. 


\section{Conclusion}

The potential use of FT-NIR reflectance spectroscopy as a non destructive method for sorting intact açaí and juçara fruits based on total anthocyanin and soluble solids content was demonstrated. The species specific TAC models were characterized by a biascorrected RMSE $\mathrm{P}_{\mathrm{P}}$ of $3.7 \mathrm{~g} \mathrm{~kg}^{-1} \mathrm{TAC}$ and $3.6 \mathrm{~g} \mathrm{~kg}^{-1} \mathrm{TAC}$ for juçara and açaí fruit, respectively. Such sorting would improve the current practice of sporadic destructive assessment of small samples of incoming lots of fruit, and allow for high TAC fruit to be targeted to specific market, e.g. for use as natural colorants or pharmaceutical products (nutraceuticals).

PCA showed that the main factors influencing spectral variation were species and the growth conditions. PLS model coefficients for TAC and SSC were similar, indicating the models for one attribute was based on a correlation to the other attribute.

Future studies could compare this technique to the assessment of anthocyanin content using visible spectroscopy or fluorescence, or consider the use of hyperspectral imaging for ease of application to sorting of fruit on a belt conveyor.

\section{Acknowledgements}

The authors would like to thank the Fundação de Amparo à Pesquisa do Estado de São Paulo (FAPESP) for fund this research (Proc. 2008/51408-1, 2011/19669-2) and for providing the BEPE fellowship (Proc. 2013/0.6089-3).

\section{References}

A.O.A.C., 1997. Association of Official Analytical Chemists: Official methods of analysis - met. 920.151.16., Cunniff, Washington., ed. Patricia.

A.O.A.C., 2006. Official methods of analysis of the Association of Official Analytical Chemists- met. 2005-02., Cuniff, Arlington., First Ed. Patrícia.

Borges, D.S., Campelo, G., Vieira, G.K.F., Copetti, C., Valdemiro, G.L., Zambiazi, R.C., Mancini Filho, J., Fett, R., 2011. Chemical characterization, bioactive compounds, and antioxidant capacity of jussara (Euterpe eduli) fruit from the Atlantic Forest in southern Brazil. Food Res. Int. 44, 2128-2133.

BRASIL, 2000. Intrução normativa, no 1. Estabelece o regulamento técnico para a fixação dos padrões de identidade e qualidade para a polpa de fruta. Diário Oficial da República Federativa do Brasil, Brasília, 10 jan. 2000. Seção 1, n.6, p. 54-58.

Brito, E.S., Araújo, M.C.P., Alves, R.E., Carkeet, C., Clevidence, B.A., Novotny, J.A., 2007. Anthocyanins present in selected tropical fruits: acerola, jambolao, jussara, and guajiru. J. Agr. Food Chem. 55, 9389-9394.

Calvi, G.P., Pina-Rodrigues, F.C., 2005. Fenologia e produção de sementes de Euterpe edulis-Mart.Em trecho de floresta de altitude no município de Miguel PereiraRJ. Rev. Univ. Rural Sér. Ci. Vida. 25, 33-40.

Cozzolino, D., Esler, M.B., Dambergs, R.G., Cynkar, W.U., Boehm, D.R., Francis, I.L., Gishen, M., 2004. Prediction of colour and pH in grapes using a diode array spectrophotmeter. J. Near Infrared Spectrosc. 12, 105-111.

Cunha Junior, L.C., Nardini, V., Khatiwada, B.P., Teixeira, G.H.A., Walsh, K.B., 2005. Classification of intact açaí (Euterpe oleracea Mart.) and juçara (E. edulis Mart.) fruits based on dry matter content by means of near infrared spectroscopy. Food Control 50, 630-636.

Dall' Acqua, Y.G., Cunha Júnior, L.C., Nardini, V., Lopes, V.G., Pessoa da, J.D.C., Teixeira, G.H.A., 2015. Discrimination of Euterpe Oleracea-Mart. (Açaí) and Euterpe EdulisMart. (Juçara) intact fruit using near-infrared (NIR) spectroscopy and linear discriminant analysis. J. Food Proc. Preser. v. n/a, p. n/a-n/a.

Fearn, T., 1996. Comparing standard deviations. NIR News 7, 5-6.

Ferrer-Gallego, R., Hernández-Hierro, J.M., Rivas-Gonzalo, J.C., Escribano-Bailón, M. T., 2011. Determination of phenolic compounds of grape skins during ripening by NIR spectroscopy. LWT-Food Sci. Technol. 44, 847-853.

Foods, P., 2011. Trends in Global Colorings. http://www.preparedfoods.com/articles/ 109323-trends-in-global-colorings (last modified date: 22.01.14).
Golic, M., Walsh, K.B., 2006. Robustness of calibration models based on near infrared spectroscopy for the in-line grading of stonefruit for total soluble solids content. Anal. Chim. Acta 555, 286-291.

Gordon, A., Cruz, A.P.G., Cabral, L.M.C., Freitas, S.C., Taxi, C.M.A.D., Donangelo, C.M. Marx, F., 2012. Chemical characterization and evaluation of antioxidant properties of Açaí fruits (Euterpe oleraceae Mart.). during ripening. Food Chem 133, 256-263.

Guthrie, J.A., Walsh, K.B., Reid, D.J., Liebenberg, C.J., 2005. Assessment of internal quality attributes of mandarin fruit. NIR calibration model development. Aust. J Agric. Res. 56, 405-416.

I.A.G., 2012. Boletim Climatológico Anual da Estação Meteorológica do IAG/USP/ Seção Técnica do Serviço Meteorológico - Instituto de Astronomia, Geofísica e Ciências Atmosféricas da Universidade de São Paulo, São Paulo: IAG/USP, 16, $63 \mathrm{f}$.

Inácio, M.R.C., Lima, S.M.G., Lopes, V.G., Pessoa, J.D., Teixeira, G.H.A., 2013. Total anthocyanin content determination in intact açaí (Euterpe oleracea Mart.) and palmitero-juçara (Euterpe edulis Mart.) fruit using near infrared spectroscopy (NIR) and multivariate calibration. Food Chem. 136, 1160-1164.

Kiozimi, L.K., Luís, T.C., José, P.D.C., Cunha Junior, L.C., Teixeira, G.H.A., 2013 Quantification of soluble solids in reconstituted açaí (Euterpe oleracea Mart.) pulp using near-infrared spectroscopy. Int. J. Food Sci. Technol. 48, 2514-2520.

Lammertyn, J., Peirs, A., Baerdemaeker, J., Nicolaï, B.M., 2000. Light penetration properties of NIR radiation in fruit with respect to non-destructive quality assessment. Postharvest Biol. Tec. 18, 121-132.

Malcher, E.T., Carvalho, J.C.T., 2011. The influence of seasonality on the anthocyanin concentrations in the açaí fruit (Euterpe oleracea Mart.) from the brazilian amazon. Int. J. Plant, Anim. Env. Sci. 1, 224-232.

Melo, M.J., Pina, F., Andary, C., 2009. Anthocyanins: nature's glamorous palette, In: Bechtold, T., Musssak, R. (Eds.), Handbook of Natural Colorants. 1st ed. John Wiley \& Sons, Chichester, pp. 135-150.

Naes, T., Isaksson, T., Fearn, T., Davies, T., 2002. A User-friendly Guide to Multivariate Calibration and Classification. NIR Publications, Chichester, UK, pp. 344.

Nicolaï, B.M., Beullens, K., Boblyn, E., Peirs, A., Saeys, W., Theron, K.I., Lammertyn, J., 2007. Nondestructive measurements of fruit and vegetable quality by means of NIR spectroscopy: a review. Postharvest Biol. Tec. 46, 99-118.

Norgaard, L., Saudland, A., Wagner, J., Nielsen, J.P., Munck, L., Engelsen, S.B., 2000. Interval partial least-squares regression (iPLS): a comparative chemometric study with an example from near-infrared spectroscopy. Appl. Spectrosc. 54, 413-419.

Pessoa, J.D.C., Teixeira, G.H.A., 2012. Tecnologias para inovação nas cadeias Euterpe, 1st ed. Embrapa, Brasilia, pp. 343.

Poulose, S.M., Fisher, D.R., Larson, J., Bielinski, D.F., Rimando, A.M., Carey, A.N. Shukitt-Hale, B., 2012. Anthocyanin-rich açaí (Euterpe oleracea Mart.) fruit pulp fractions attenuate inflammatory stress signaling in mouse brain BV2 microglial cells. J. Agr. Food Chem. 60, 1084-1093.

Rogez, H., Akwie, S.N., Moura, F.G., Larondelle, Y., 2012. Kinetic modeling of anthocyanin degradation and microorganism growth during postharvest storage of açaí fruits (Euterpe oleracea). J. Food Sci. 77, 1300-1306.

Rogez, H., Pompeu, D.R., Akwie, S.N., Larondelle, Y., 2011. Sigmoidal kinetics of anthocyanin accumulation during fruit ripening: a comparison between açaí fruits (Euterpe oleracea) and other anthocyanin-rich fruits. J. Food Compos. Anal. 24, 796-800.

Santos, G.C., Jardim, M.A.G., 2006. Florística e estrutura do estrato arbóreo de uma floresta de várzea no município de Santa Bárbara do Para, Estado do Para, Brasil. Acta Amaz. 36, 437-446.

Saranwong, S., Sornsrivichai, J., Kawano, S., 2001. Improvement of PLS calibration for Brix value and dry matter of mango using information from MLR calibration. J. Near Infrared Spec. 9, 287-295.

Schauss, A.G., Wu, X., Prior, R.L., Ou, B., Huang, D., Owens, J., Shanbrom, E., 2006a Antioxidant capacity and other bioactivities of the freeze-dried Amazonian palm berry, Euterpe oleracea Mart. (açaí). J. Agri. Food Chem. 54, 8604-8610.

Schauss, A.G., Wu, X., Prior, R.L., Ou, B., Patel, D., Huang, D., Kababick, J.P., 2006b. Phytochemical and nutrient composition of the freeze-dried Amazonian palm berry, Euterpe oleraceae Mart. (Acai). J. Agr. Food Chem. 54, 8598-8603.

Smith, S., 2013. Superfoods Index: top 50 foods to boost health and vitality. 1st Ed. Jane Curry Publishing.

Subedi, P.P., Walsh, K.B., 2009. Non-invasive techniques for measurement of fresh fruit firmness. Postharvest Biol. Tec. 51, 297-304.

Vieira, G.S., Cavalcanti, R.N., Meireles, M.A.A., Hubinger, M.D., 2013. Chemical and economic evaluation of natural antioxidant extracts obtained by ultrasoundassisted and agitated bed extraction from jussara pulp (Euterpe edulis). J. Food Eng. 119, 196-204. 